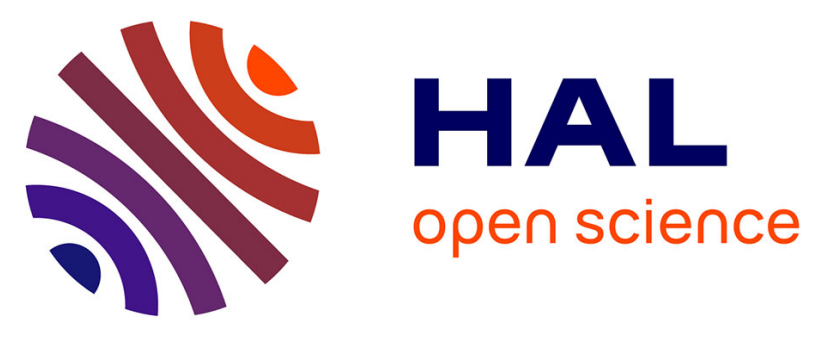

\title{
When does the Autism Spectrum Screening Questionnaire (ASSQ) predict autism spectrum disorders in primary school-aged children?
}

Marja-Leena Mattila, Katja Jussila, Sanna Kuusikko, Marko Kielinen, Sirkka-Liisa Linna, Hanna Ebeling, Risto Bloigu, Leena Joskitt, David Pauls, Irma Moilanen

\section{To cite this version:}

Marja-Leena Mattila, Katja Jussila, Sanna Kuusikko, Marko Kielinen, Sirkka-Liisa Linna, et al.. When does the Autism Spectrum Screening Questionnaire (ASSQ) predict autism spectrum disorders in primary school-aged children?. European Child and Adolescent Psychiatry, 2009, 18 (8), pp.499-509. 10.1007/s00787-009-0044-5 . hal-00535165

\section{HAL Id: hal-00535165 \\ https://hal.science/hal-00535165}

Submitted on 11 Nov 2010

HAL is a multi-disciplinary open access archive for the deposit and dissemination of scientific research documents, whether they are published or not. The documents may come from teaching and research institutions in France or abroad, or from public or private research centers.
L'archive ouverte pluridisciplinaire HAL, est destinée au dépôt et à la diffusion de documents scientifiques de niveau recherche, publiés ou non, émanant des établissements d'enseignement et de recherche français ou étrangers, des laboratoires publics ou privés. 


\title{
When does the Autism Spectrum Screening Questionnaire (ASSQ) predict autism spectrum disorders in primary school-aged children?
}

\author{
Marja-Leena Mattila $\cdot$ Katja Jussila $\cdot$ Sanna Kuusikko • Marko Kielinen · \\ Sirkka-Liisa Linna · Hanna Ebeling · Risto Bloigu · Leena Joskitt • \\ David Pauls · Irma Moilanen
}

Received: 19 February 2009/Accepted: 7 May 2009/Published online: 14 July 2009

(C) Springer-Verlag 2009

\begin{abstract}
The aims of this study were, firstly, to study the association between parents' and teachers' ratings for the Finnish version of the Autism Spectrum Screening Questionnaire (ASSQ), secondly, to find out whether the original cut-off scores of the ASSQ identify primary school-aged children with Asperger syndrome (AS) or autism by using the Finnish ASSQ, and thirdly, to evaluate the validity of the ASSQ. Parents and/or teachers of higher-functioning (full-scale intelligence quotient $\geq 50$ ) 8-year-old total population school children $(n=4,408)$ and 7-12-year-old outpatients with AS/autism $(n=47)$ completed the Finnish version of the ASSQ. Agreement between informants was slight. In the whole total population, low positive correlation was found between parents' and teachers' ratings,
\end{abstract}

M.-L. Mattila ( $₫) \cdot$ K. Jussila $\cdot$ S. Kuusikko $\cdot$ H. Ebeling · L. Joskitt · I. Moilanen

Clinic of Child Psychiatry, University Hospital of Oulu,

University of Oulu, P.O. Box 26, 90029 Oulu, Finland

e-mail: marja-leena.mattila@ fimnet.fi

K. Jussila

e-mail: katja.jussila@oulu.fi

S. Kuusikko

e-mail: sanna.kuusikko@gmail.com

H. Ebeling

e-mail: hanna.ebeling@oulu.fi

L. Joskitt

e-mail: leena.joskitt@oulu.fi

I. Moilanen

e-mail: irma.moilanen@oulu.fi

M. Kielinen

Department of Educational Sciences and Teacher Education, University of Oulu, P.O. Box 2000, 90014 Oulu, Finland

e-mail: marko.kielinen@oulu.fi while in the sample of high-scoring children the correlation turned out to be negative. A cut-off of 30 for parents' and teacher's summed score and 22 for teachers' single score is recommended. A valid cut-off for parents' single score could not been estimated. The clinicians are reminded that the ASSQ is a screening instrument, not a diagnosing instrument. The importance of using both parents' and teachers' ratings for screening in clinical settings is underlined.

Keywords Asperger syndrome - Pervasive developmental disorders · Autism spectrum disorders . Autism Spectrum Screening Questionnaire (ASSQ) . Screening 


\section{Introduction}

According to a study by Howlin and Asgharian [11], parents of children with autism were generally aware of developmental problems by 18 months of age, and parents of children with Asperger syndrome (AS) at around 30 months of age, while the average age of confirmed diagnoses was around 5.5 years in the autism group and 11 years in the AS group. The diagnoses of autism spectrum disorders (ASD) thus seemed to be assigned much later than the time when parents notice developmental deviances in their child. In order to help to identify ASDs, a number of screening instruments have been developed, many of them for more severely handicapped children with autism [e.g. 4, 5, 13] or for children with ASD at all intelligence levels [e.g. 7, 8, 21]. Additionally, some screening instruments have been developed and validated precisely for higher-functioning phenotypes [e.g. 9, 10, 22, 27].

The Autism Spectrum Screening Questionnaire (ASSQ) [10] was the first screening instrument developed precisely for AS. Initially it was known as the Asperger Syndrome Screening Questionnaire. The rationale for evaluation of the ASSQ in AS and other ASDs in higher-functioning children was the fact that there is a clear overlap of symptoms at behavioural level, reflected in the International Classification of Mental and Behavioural Disorders (ICD-10, WHO) [28] and Diagnostic and Statistical Manual of Mental Disorders (DSM-IV, APA) [2] criteria for ASDs. Originally designed in Sweden in Swedish, the questionnaire was developed specifically for teacher screening in children aged 7-16 years with normal intelligence or mild mental retardation. However, the Swedish cut-off scores were determined later for both parents' and teachers' ratings $[9,10]$. The ASSQ has been used in clinical settings in Finland since the 1990s and it has also been translated into other languages (English [10], Lithuanian [15], Norwegian [19]). No other validated screening instrument especially for AS was available when the ASSQ was imported from Sweden to Finland.

In reports on child psychiatric symptoms, agreement between parents' and teachers' ratings is generally low to moderate $[1,14]$. Agreement between informants has been studied not only in general child psychiatric symptoms, but also in autistic features [19, 24]. Szatmari et al. [24] reported slight agreement between parents' and teachers' ratings $(\kappa=0.17)$ in the Autism Behavior Checklist (ABC; [13]) when assessing children with pervasive developmental disorders (PDD). The results were suggested to be partly explained by real differences in behaviour at school and at home. In turn, Posserud et al. [19] reported low-to-moderate agreement between parents and teachers when assessing autistic features in a total population of 7-9-year-old children by using the ASSQ. As a consequence of low-to-moderate agreement, it is well grounded to assume that the number of informants-a multi-informant versus a single-informant approach-may influence diagnostics $[9,15,18,23]$. Because of large differences across informants, the need to gather information from both families and schools when screening for ASDs was also suggested by Posserud et al. [19].

The purpose of our study was threefold: first, to study the association between parents' and teachers' ratings on the Finnish version of the ASSQ, second, to find out whether the original cut-off scores recommended by Ehlers et al. [10] are able to identify Finnish higher-functioning [full-scale intelligence quotient $(\mathrm{FSIQ}) \geq 50$ ] primary school-aged children with AS or autism and whether using multi-informant ratings could increase the value of the ASSQ as a screening instrument, and third, to evaluate the sensitivity, specificity, positive predictive value (PPV), negative predictive value (NPV), likelihood ratio (LR), per cent agreement ( $\%$ agreement) and kappa on the Finnish ASSQ.

\section{Methods}

\section{Participants}

The participants of this study were drawn from two ongoing studies concerning higher-functioning (FSIQ $\geq 50$ ) children with AS or autism: (1) the "total population study" [18], consisting of 4,408 children (FSIQ $\geq 50$ ) and (2) the "outpatient study" of high-functioning (FSIQ $\geq 80$ ) outpatient children with AS/autism, consisting of 34 children. The participants were then divided into three partly overlapping groups: (1) "total population group": 4,408 eightyear-old children (mean age 8.3, range 7.8-8.8) from the "total population study" including 13 outpatients with ASD (FSIQ $\geq 50$ ), (2) "validation sample": 104 eight-year-old children (mean age 8.3, range 7.8-8.8) from the "total population study" including the 13 outpatients mentioned above with ASD (FSIQ $\geq 50$ ) and (3) "outpatient group": 47 outpatient children aged 7-12 (mean age 9.7, range 7.7-12.2) with ASD (FSIQ $\geq 50$ ) from Oulu University Hospital $(n=43)$ or at Tahkokangas Service Centre in Oulu (i.e. a rehabilitation centre for mentally handicapped, $n=4$ ) including the above-mentioned 13 outpatients with ASD from the "total population study".

In Finland, compulsory education offers equal educational possibilities for every child aged 7-16 years. From the age of 7 to the age of 12 , children attend primary school, and from 13 to 16 years they attend secondary school. All children undergo developmental examinations in children's health care centres several times before school age. If any developmental deviances are found or mental 
retardation is suspected, the child is referred to more detailed investigations and school readiness examinations also including the determination of IQ. Parents thus get to know the cognitive level of their child. If mental retardation is assigned, the child is referred to prolonged compulsory education and further service (at Tahkokangas Service Centre in the Oulu University Hospital area).

\section{Registered ASD diagnoses}

Of the 47 ASD outpatients in this study, 32 had the registered diagnosis of AS, 3 had infantile autism with mild mental retardation, whereas 11 had "AS traits" and 1 had "autistic traits" with mild mental retardation in the records of the Oulu University Hospital and/or Tahkokangas Service Centre. AS and AS traits diagnoses had been assigned based on the ICD-10 criteria regarding current behaviour. Thus, a differential diagnosis between AS and high-functioning autism (HFA) had not been made. The diagnosis "AS traits" refers to the features of AS, and "autistic traits" to the features of autism.

\section{Procedure}

The studies were approved by the ethical committee of Oulu University Hospital. The school inspector, the superintendents of all 43 municipalities and all 329 school principals were informed and permission was asked to carry out the screening phase of the "total population study". Written informed consent was obtained from parents and from children aged 12-13 years.

Total population study

\section{Screening phase of the study}

The "total population study" started in September 2000 in the Northern Ostrobothnia Hospital District area [18] (Fig. 1). All 8-year-old children born in 1992 attending primary or special school and living in this area in autumn 2000 were chosen for the target population, $n=5,484$ (Statistics Finland, 31st of December, 2000). The teachers of these children were given an information package concerning the study, including lectures on AS and the ASSQ, after which the questionnaires were distributed to parents by teachers. The parents were required to provide a written informed consent to participate in the study and were asked to complete the ASSQ and a developmental questionnaire, in which possible AS and autism diagnosis and possible mental retardation were asked about. In the case of mental retardation, the level (mild, moderate, severe or profound) was also inquired in the developmental questionnaire.

Parent questionnaires were returned to teachers in closed envelopes with written permission to participate on the

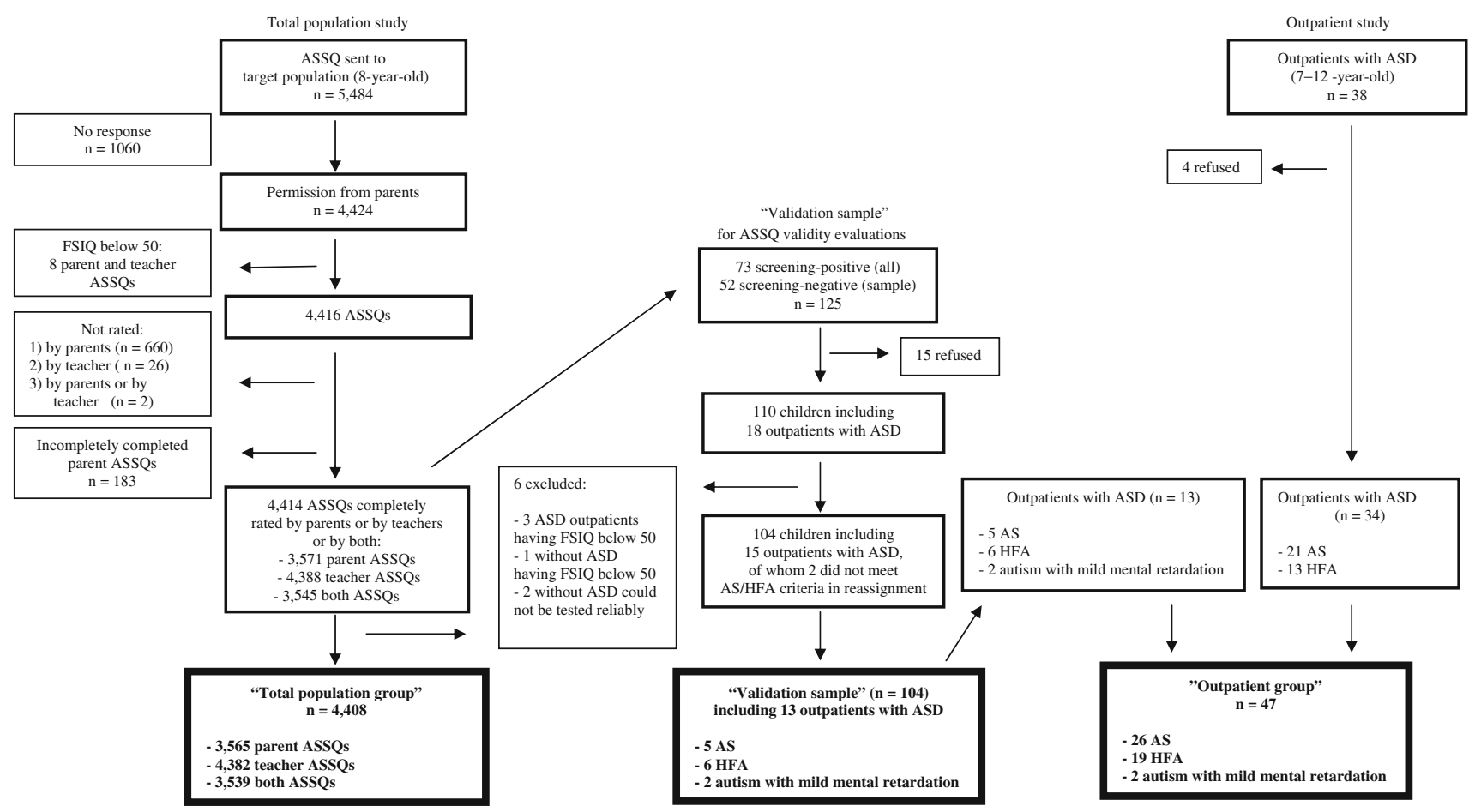

Fig. 1 Study design and subject flow. ASSQ Autism Spectrum Screening Questionnaire, $A S D$ autism spectrum disorder, $A S$ Asperger syndrome, $H F A$ high-functioning autism, FSIQ full-scale intelligence quotient 
cover. Parents of 4,424 children $(80.7 \%)$ gave permission. After permission from parents the teachers of these children completed the ASSQ. The teachers were also asked about the child's curriculum: general or special needs education (i.e. partly or completely adjusted education or education for children with mild, moderate, severe or profound mental retardation, or any other special education). Finally, the teachers returned all questionnaires to the researchers. Based on parents' reports on the level of mental retardation with complementary curriculum information from teachers, eight children were excluded as having moderate or severe mental retardation. A total of 4,416 children remained in the study.

\section{Missing data}

Of these 4,416 children, 660 did not have parents', 26 teachers' and two did not have either parents' or teachers' ratings, and 183 parents' ASSQs were discarded due to missing information (i.e. 1-25 items were missing). Missing items in teachers' ASSQs were asked either by regular mail or by telephone, and all teachers' ASSQs were thus successfully completed. Eventually, 4,414 children remained, with 3,571 parents' and 4,388 teachers' ASSQs.

\section{"Validation sample" for ASSQ validity evaluations}

Of the 4,414 children, 125 were included in the "validation sample" in which the ASSQ validity was evaluated. The sample of 125 children consisted of all 73 screening-positive (parent ASSQ $\geq 19$ and/or teacher ASSQ $\geq 22$; [10]) children and a sample of 52 screening-negative children. Of the 73 screening-positive children, 24 were screeningpositive only in parents', 36 only in teachers' and 13 in both ratings. The inclusion criteria of screening-negative children were based on two Swedish articles [10, 12]: teacher ASSQ 17-21 $(n=28)$ [12]; parent ASSQ 7-18 and teacher ASSQ 9-16 $(n=24)$ [10]; these minimum scores, parent ASSQ score of 7 and teacher ASSQ score of 9, were selected from the Receiver Operating Characteristic (ROC) curves in the study of Ehlers et al. [10] with sensitivity of $95 \%$. Of the 125 children, $110(88.0 \%)$ agreed to proceed, 65 of whom were screening-positive $(89.0 \%)$ and 45 screening-negative $(86.5 \%)$. Thus, 15 children declined, two of whom with AS/AS traits diagnosis according to the parents' developmental questionnaire.

To find out the outpatients with registered ASD diagnosis in the "validation sample", developmental history questionnaires completed by parents and patient records at the University Hospital of Oulu and Tahkokangas Service Centre were studied. Permission to check the patient records was asked from the parents. Of these 110 children, 18 were outpatients with ASD diagnosis (4 AS, 6 AS traits, 1 AS suspected, 1 HFA, 3 autism with mild mental retardation, 1 autismus infantilis, 1 PDD with mild mental retardation, and 1 autistic traits with mild mental retardation).

\section{Diagnostic re-assignments}

These 18 outpatients with registered ASD diagnosis underwent diagnostic examinations. The Autism Diagnostic Interview-Revised (ADI-R; [16]), as a structured developmental and symptom history from parent(s), and the Autism Diagnostic Observation Schedule (ADOS; [17]), module 3, as a semi-structured child observation, were administered and videotaped by a paediatrician (M.-L.M.), clinically experienced in ASDs, and the Wechsler Intelligence Scale for Children-Third Revision (WISC-III) [25] was administered by two psychologists. Parents were also asked to supplement incompletely completed ASSQs $(n=1$; four items missing) or fulfil non-completed ASSQs $(n=3)$.

Three screening-positive outpatients with ASD were now tested as having an FSIQ below 50, and they were excluded, leaving 15 outpatients with ASD for further reevaluations. In the "validation sample", the WISC-III was administered to three children without any registered ASD diagnosis to find out the accurate FSIQ level. One screening-positive child had earlier been diagnosed to have mild/moderate mental retardation; the FSIQ of that child was now determined as below 50. Two screening-negative had severe neurological disability and the previous IQ level was unsure; these two still could not be tested reliably. All three children were excluded from the study.

After diagnostic examinations, school day observations of five children were undertaken to obtain more information. The observations were performed by an autism researcher of our team, a Master of Education (M.K.) blind to the primary examinations. The observation of each child lasted an entire school day, including direct observation during lessons and breaks, "structured interview" (ASSQ) and non-structured discussion with the teacher. After that, re-evaluations of 15 outpatients with ASD were performed by experienced clinicians (S.-L.L. and M.-L.M.) by reviewing all available data (ADI-R, ADOS tapes, ASSQs, patient records and school day observations). M.K. participated in the re-evaluation meetings for the five children whose school day was observed. The ICD-10 research criteria were then fulfilled, item by item, based on the consensus between S.-L.L. and M.-L.M. Two outpatients with ASD (one AS traits and one AS suspected) did not meet the ICD-10 research criteria for AS or autism. Finally, 13 were re-assigned as ASD, 5 of them as AS, 6 as HFA, and 2 as autism with mild mental retardation. Six of the 13 outpatients with re-assigned ASD were registered as ASD in hospital patient records after parent and teacher ASSQ ratings (i.e. after the screening phase of our study). 
Final groups in the "total population study"

Eventually, 4,408 (80.4\%) children with ASSQ made up the "total population group", including 3,565 (80.9\%) parents' ASSQs, and 4,382 (99.4\%) teachers' ASSQs, 3,539 of which $(80.3 \%)$ rated by both, all of the children having an FSIQ $\geq 50$ and no items missing on the ASSQs.

In addition, of the 4,408 children, 61 screening-positive and 43 screening-negative made up a "validation sample" $(n=104)$, all rated by parents and 103 by teachers, including 13 outpatients with registered and verified ASD. The ASSQ validation was to be evaluated in the "validation sample".

\section{Outpatient study}

The "outpatient study" started in January 2003 and is part of a larger research project concerning high-functioning (FSIQ $\geq 80$ ) outpatient children with AS or autism of Oulu University Hospital (Fig. 1). All 7-12-year-old primary school-aged outpatients with AS or AS traits, excluding outpatients born in 1992 (i.e. the outpatients already in the "total population study"), were invited $(n=38)$, and 34 (89.5\%) participated. All parents completed the ASSQ.

The ASD diagnoses of 34 outpatients were re-assigned by using the ADI-R [16] to acquire developmental and symptom history from parent(s), and by using the ADOS, module 3 [17] to observe the child's behaviour and communication skills. The examinations were administered and videotaped by a research psychologist (K.J.). The patient records of all participants were studied. The diagnoses were then redefined according to the ICD-10 research criteria, based on information obtained with the ADI-R, ADOS and from patient records, by a psychologist (K.J.) consulting an experienced clinician (M.-L.M.) when a second opinion was needed. Development in the first 3 years of life was now taken into account. In these evaluations 21 children met the ICD-10 research criteria for AS and 13 for autism.

The teachers of all 34 children were asked to complete the ASSQ 1 year later. Questionnaires were sent by regular mail to the parents, who were asked to complete the consent and then give the questionnaire to their child's teacher. The questionnaire was resent twice if the ASSQ was not returned by the teacher. One 12-year-old child did not give permission to the teacher to complete the ASSQ. Finally, 33 teachers completed the ASSQ with parents' (and child's) permission.

Eventually, the "outpatient group" consisted of 47 children (13 from the "total population study" and 34 from the "outpatient study"), 26 of whom met the re-assigned diagnosis for AS, 19 for HFA and 2 for autism with mild mental retardation. The ASSQ was completed by all parents and by 46 teachers.
Assessment instruments

\section{Autism Spectrum Screening Questionnaire}

The ASSQ [10] comprises 27 items rated on a 3-point scale, 0 indicating normal, 1 some abnormality and 2 definite abnormality. The range of score is $0-54$. Eleven items tap topics regarding social interaction, six cover communication problems and five refer to restricted and repetitive behaviour. The remaining five items embrace motor clumsiness and other associated symptoms including motor and vocal tics. Completing the ASSQ takes $10 \mathrm{~min}$. Cut-off scores of 19 or more for parents' and 22 or more for teachers' ratings have been recommended in Sweden for screening to identify ASDs in children with normal intelligence or mild mental retardation in a clinical setting $[9,10]$. The content and concurrent and discriminating validity of the questionnaire have been studied, and it has been published by Ehlers et al. [10].

The ASSQ was first translated into Finnish by two clinically experienced psychologists and then back-translated into Swedish by an official Swedish translator. The final version was completed based on comparison between the original and the back-translated Swedish forms by the authors and on comments by child neurologists at Oulu University Hospital. On the 3-point scale, we decided to exclude the word "definite" from the alternative "definite abnormality" in the Finnish version because of clinical experience of Finnish parents' reluctance to assess their children's features as "definite".

\section{Autism Diagnostic Interview-Revised and Autism Diagnostic Observation Schedule}

The ADI-R [16] is a standardized investigator-based parent interview developed to elicit a full range of information across all three main symptom areas needed to produce a diagnosis of autism and to assist in the assessment of related PDDs. The ADI-R was translated into Finnish by two clinical psychologists in the 1990s and then backtranslated into English by an official English translator. After comparison the final Finnish version was completed by a group of professionals in the field of ASDs, all trained in the use of the ADI-R.

The ADOS [17] is a semi-structured assessment of social interaction, communication and play or imaginative use of materials for individuals who may have autism or other PDDs. The ADOS comprises four modules based on the verbal level of the subject. Module 3 was used in this study and was translated into Finnish by an official English translator.

The physicians (M.-L.M. and S.-L.L.), psychologist (K.J.) and Master of Education (M.K.) who participated in 
the diagnostic process have been trained in the use of the ADI-R and ADOS for research purposes. The cut-off scores of the algorithms are standardized for autism and ASDs, but there are no algorithms precisely for AS. The ADI-R and ADOS algorithms were not used in this study.

\section{Wechsler Intelligence Scale for Children-Third Revision}

IQ was measured by the WISC-III [25]. Throughout this study, the diagnosis of "HFA" is used in subjects with autism who had an FSIQ $\geq 70$, and the FSIQ of "higherfunctioning" subjects is defined to be $\geq 50$.

\section{Patient records}

The University Hospital of Oulu and/or Tahkokangas Service Centre records of the subjects in the "validation sample" and in the "outpatient group" were studied. Early development was verified.

\section{Statistical analyses}

The distributions of total ASSQ scores were skewed in the "total population group", while total ASSQ scores were normally distributed in the "validation sample" and in the "outpatient group". In skewed distributed data and in small samples, non-parametric Mann-Whitney's $U$-test $(Z)$ and Wilcoxon's test were used. In normally distributed data, analyses were performed by parametric $t$-test for two independent samples and paired $t$-test. Correlations between parents' and teachers' ratings were estimated using Spearman's rho in skewed distributed data and in small samples, and Pearson correlation in normally distributed data. Correlations' $P$-values are reported as onesided and others' as two-sided. $P$-values $<0.05$ were interpreted as significant. ROC analyses were performed to assess the discriminating validity of the ASSQ. Analyses were produced with the Statistical Package for Social Sciences version 16.0 for Windows.

\section{Results}

Medians and means in ratings and differences between ratings

The median in parents' ratings was $24.0(n=47)$ and in teachers' ratings was $27.5(n=46)$ in the "outpatient group"; the corresponding figures were $1.0(n=3,565)$ and $0.0(n=4,382)$ in the "total population group". Mean differences between "outpatient group" and "total population group" in parents" $(M=24.3$ vs. $2.0 ; P<0.001)$ and teachers' ratings $(M=27.2$ vs. $1.5 ; P<0.001)$ were significant. In the "total population group", mean interrater difference between parent and teacher scorings was 0.4 $(M=2.0$ vs. $1.6 ; Z=-11.209 ; n=3.539 ; P<0.001)$, and in the "validation sample", $-5.8(M=12.2$ vs. 18.0 ; 95\% confidence interval $[\mathrm{CI}]-8.7$ to $-3.0 ; n=103$; $P<0.001)$. The mean difference for parents' scores in the "outpatient group" between the subjects $(n=6)$ rated before and the ones $(n=41)$ rated after getting outpatient ASD diagnosis was significant ( $M=18.0$ vs. 25.2; $Z=-1.963 ; P=0.049$ ) (Table 1).

In the "outpatient group", means between males and females did not differ significantly in parents' $(M=23.7$ vs. 26.2) and teachers' ( $M=26.6$ vs. 29.2$)$ ratings, whereas in the "total population group", males were rated significantly higher than females by parents $(M=2.3$ vs. $1.7 ; Z=-4.219 ; P<0.001)$ and by teachers $(M=2.2 \mathrm{vs}$. $0.9 ; Z=-8.568 ; P<0.001$ ) (Table 1). The ASSQ scores did not differentiate children with AS and HFA (Fig. 2).

\section{Association between ratings}

Kappa (к) between parents and teachers was 0.207 $(n=3.539 ; P<0.001)$ in the "total population group", and $0.097(P=0.038)$ in subjects $(n=337)$ from the 14 schools where teachers were known not to participate in the lectures on AS and the ASSQ.

The correlation coefficient between parents' and teachers' ratings was $0.258(P<0.001)$ in the "total population group", and $0.205(P<0.001)$ in children $(n=337)$ from the 14 schools where teachers were known not to participate in the lectures on AS and the ASSQ. In turn, correlation coefficient between parents' and teachers' ratings was negative in the "validation sample" $(r=-0.368$, $P<0.001$ ) (Fig. 3), and it was also negative in highscoring children $(n=42$; parent ASSQ $\geq 7$ or teacher ASSQ $\geq 9$ ) from the 14 schools where teachers were known not to participate in the lectures on AS and the ASSQ $(r=-0.421, P=0.003)$.

Participants scoring at or above the original cut-off scores in the "outpatient group"

Of the "outpatient group", mainly rated at the interval of 1 year, $81.1 \%$ of parents' $(n=37), 72.2 \%$ of teachers' ( $n=36)$ and $97.3 \%$ of either parents' or teachers' ratings ( $n=37$ ) were at or above the original cut-offs of the ASSQ (parents $\geq 19$, teachers $\geq 22$ ) [10], and only one subject fell below both cut-offs (18 from mother and 13 from teacher). Ratings were also analysed separately in the group of ten children with AS/autism from the "outpatient group", rated at the same time by both informants: $60.0 \%$ of parents', $80.0 \%$ of teachers' and $90.0 \%$ of either parents' or teachers' ratings were at or above the original cut-offs 
Table 1 Means of total ASSQ scores and differences between total ASSQ scores

\begin{tabular}{|c|c|c|c|}
\hline & $n$ & $M(\mathrm{SD})$ & Range \\
\hline \multicolumn{4}{|l|}{ Total population group } \\
\hline \multicolumn{4}{|l|}{ All } \\
\hline Parents $^{1}$ & 3,565 & $2.0(3.5)$ & $0-30$ \\
\hline Teachers $^{2}$ & 4,382 & $1.5(3.9)$ & $0-49$ \\
\hline \multicolumn{4}{|l|}{ Males } \\
\hline Parents $^{3}$ & 1,744 & $2.3(3.9)$ & $0-30$ \\
\hline Teachers $^{4}$ & 2,161 & $2.2(4.7)$ & $0-49$ \\
\hline \multicolumn{4}{|l|}{ Females } \\
\hline Parents $^{3}$ & 1,821 & $1.7(3.0)$ & $0-28$ \\
\hline Teachers ${ }^{4}$ & 2,221 & $0.9(2.8)$ & $0-43$ \\
\hline \multicolumn{4}{|l|}{ Outpatient group } \\
\hline \multicolumn{4}{|l|}{ All } \\
\hline Parents $^{1}$ & 47 & $24.3(8.5)$ & $8-40$ \\
\hline Teachers $^{2}$ & 46 & $27.2(9.5)$ & $4-43$ \\
\hline \multicolumn{4}{|l|}{ Males } \\
\hline Parents $^{5}$ & 37 & $23.7(7.9)$ & $8-38$ \\
\hline Teachers $^{6}$ & 36 & $26.6(8.8)$ & $4-43$ \\
\hline \multicolumn{4}{|l|}{ Females } \\
\hline Parents $^{5}$ & 10 & $26.2(10.8)$ & $10-40$ \\
\hline Teachers $^{6}$ & 10 & $29.2(12.0)$ & $13-43$ \\
\hline \multicolumn{4}{|l|}{ Parents } \\
\hline Before outpatient ASD diagnosis ${ }^{7}$ & 6 & $18.0(7.0)$ & $8-26$ \\
\hline After outpatient ASD diagnosis ${ }^{7}$ & 41 & $25.2(8.4)$ & $8-40$ \\
\hline \multicolumn{4}{|c|}{$\begin{array}{l}1 \quad P<0.001 \text { for parents' ratings between "total population group" } \\
\text { and "outpatient group" }\end{array}$} \\
\hline \multicolumn{4}{|c|}{$\begin{array}{l}2 \quad P<0.001 \text { for teachers" ratings between "total population group" } \\
\text { and "outpatient group" }\end{array}$} \\
\hline \multicolumn{4}{|c|}{$\begin{array}{l}3 \quad P<0.001 \text { for parents' ratings between males and females in "total } \\
\text { population group" }\end{array}$} \\
\hline \multicolumn{4}{|c|}{$\begin{array}{l}4 \quad P<0.001 \text { for teachers' ratings between males and females in } \\
\text { "total population group" }\end{array}$} \\
\hline \multicolumn{4}{|c|}{$\begin{array}{l}5=\text { ns. for parents' ratings between males and females in "out- } \\
\text { patient group" }\end{array}$} \\
\hline \multicolumn{4}{|c|}{$\begin{array}{l}6 P=\mathrm{ns} \text {. for teachers' ratings between males and females in } \\
\text { "outpatient group" }\end{array}$} \\
\hline \multicolumn{4}{|c|}{$\begin{array}{l}7 P=0.049 \text { for parents' ratings between children rated before } \\
\text { outpatient ASD diagnosis and after outpatient ASD diagnosis in } \\
\text { "outpatient group" }\end{array}$} \\
\hline
\end{tabular}

and only one subject fell below the cut-off scores (11 from mother and 19 from teacher).

ASSQ validation in the "validation sample"

Discriminant validity was studied using the ROC analyses for ASSQ scores of parents, teachers and summed scores of parents and teacher in the "validation sample". ROC analyses of the parent-rated ASSQs estimated no valid
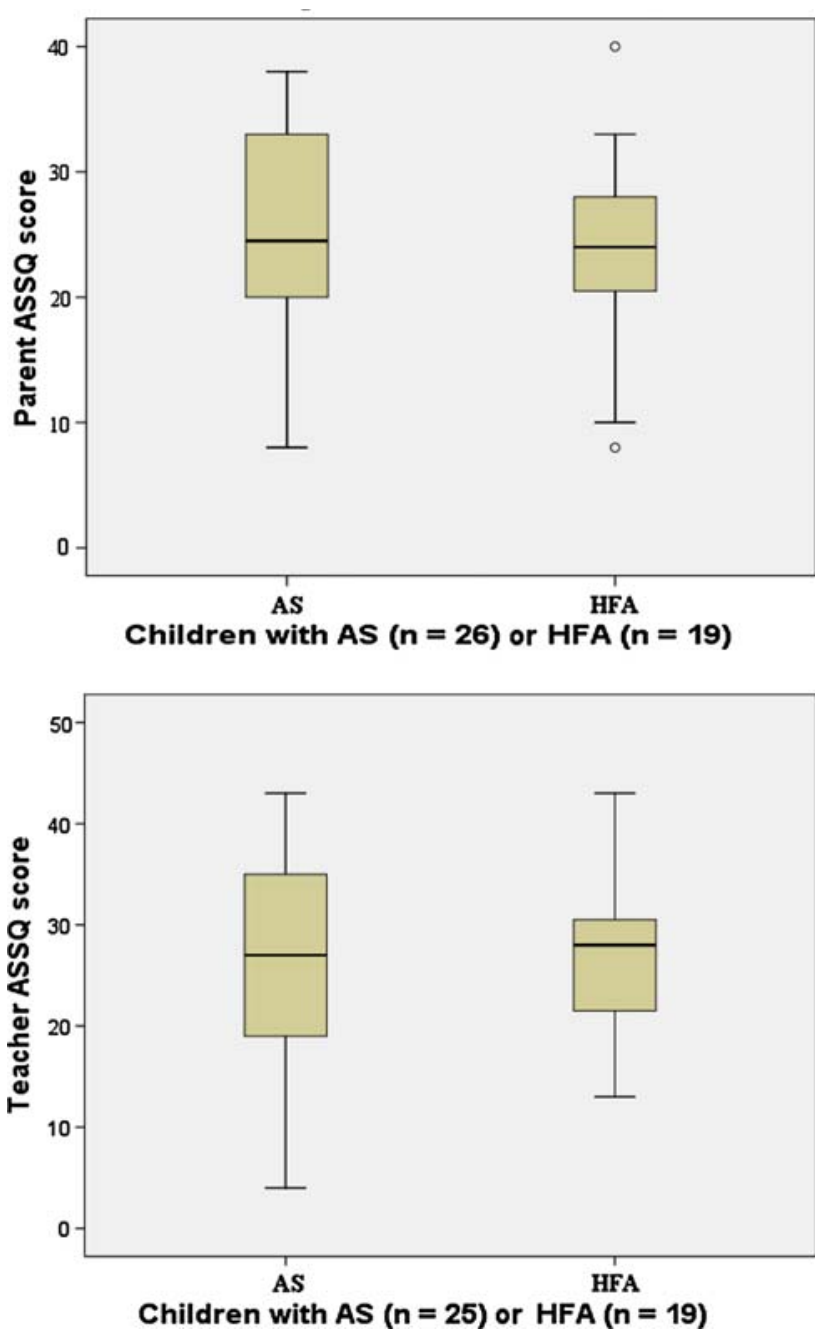

Fig. 2 Means and ranges of total scores on the ASSQ rated by parents and by teachers in children with AS or HFA. ASSQ Autism Spectrum Screening Questionnaire, $A S$ Asperger syndrome, HFA high-functioning autism

cut-off (Fig. 4, Table 2). The teacher-rated ASSQs yielded the cut-off of 22, with sensitivity of 0.85 and specificity of 0.69 . However, the cut-off of 30 with sensitivity of 1.00 and specificity of 0.73 was the best estimation for summed scores of parents and teacher. For the teacher cut-off of 22, PPV was 0.28, NPV 0.97, LR 2.72, \% agreement 70.9 and kappa 0.29 (95\% CI: 0.05-0.52). The corresponding statistics for the summed parents and teacher cut-off of 30 were as follows: PPV 0.35, NPV 1.00, LR 3.75, \% agreement 76.7 and kappa 0.41 (95\% CI: 0.20-0.62) (Table 2).

\section{Discussion}

This study presents how the Finnish ASSQ works as a screening instrument. The ASSQ seems to find the higher- 


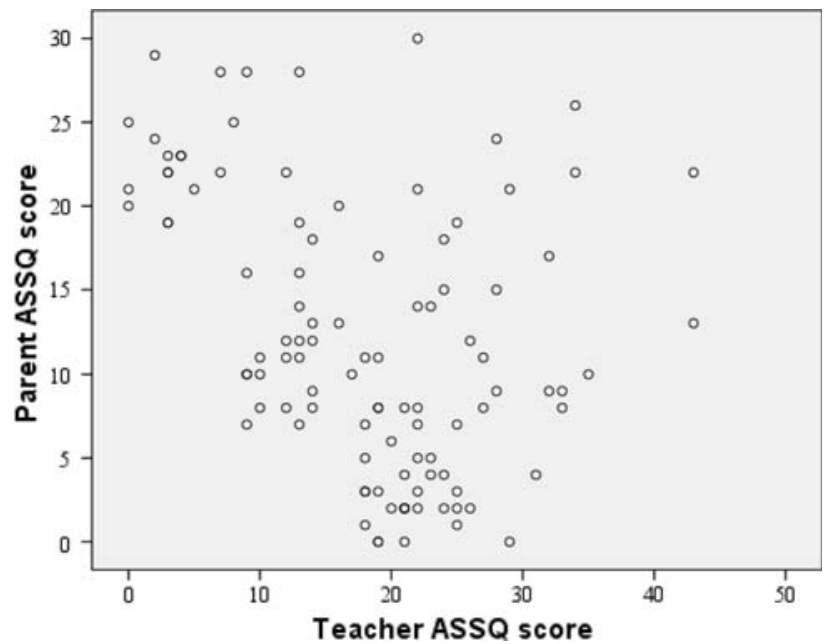

Fig. 3 Correlation $(r=-0.368)$ between parents' and teachers' ratings in the "validation sample"

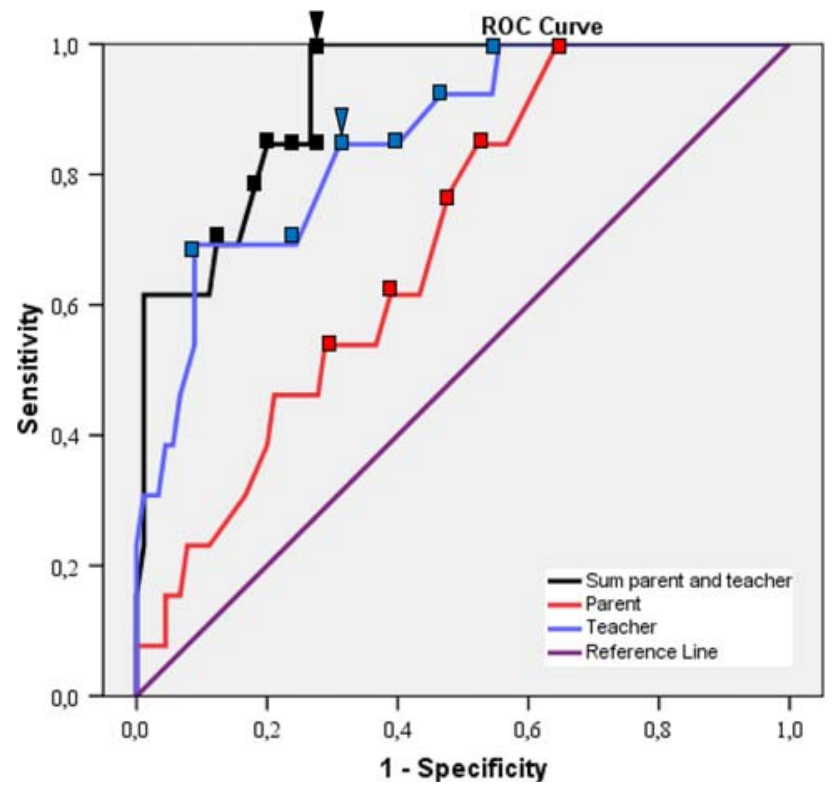

Fig. 4 ROC curves for the prediction of AS/autism from summed parents' and teacher's ASSQ score, teachers' single ASSQ score and parents' single ASSQ score in the "validation sample". $R O C$ receiver operating characteristic, AS Asperger syndrome, ASSQ Autism Spectrum Screening Questionnaire

functioning children with AS/autism. The medians and means of the ASSQ scores in parents' and teachers' ratings were significantly higher in children with AS/autism ("outpatient group") than in the total population ("total population group"). In addition, parents scored children who were rated on the ASSQ in our study after receiving ASD diagnosis at the outpatient clinic significantly higher than children who were rated on the ASSQ in our study before receiving ASD diagnosis at the outpatient clinic. This might indicate that parents of the children who were already diagnosed as ASD at the outpatient clinic probably knew better what kind of features they had to assess, leading them to rate their children higher, or that they already knew what was causing their children's symptoms and they were more educated to perceive certain symptoms typical of ASD. Based on this discovery, it may be assumed that parents might score lower on the ASSQ at diagnostic examinations in clinical settings, because they usually do not know very much about ASDs when their child is referred to the outpatient clinic. After the child has been diagnosed with ASD parents obtain knowledge about ASDs, and they might score higher on the ASSQ. However, the number of subjects $(n=6)$ who were not diagnosed as ASD before ASSQ ratings was low. Therefore, the effect of parents' awareness of diagnosis on their scoring should be analysed in larger samples. The teachers' scores were at the same level irrespective of whether the outpatient ASD diagnoses were already given or not. However, we did not know who of the teachers were aware of the outpatient ASD diagnosis.

No crucial score difference between genders was found in the "outpatient group". However, reliable conclusion about the gender non-differences in higher-functioning subjects with ASD has to be treated with prudence because of the wide score ranges and the small number of females in the "outpatient group" $(n=10)$. Baron-Cohen et al. [6] also reported that male and female scores (on the Autism Spectrum Quotient; AQ) did not differ significantly among the AS/HFA group; however, the number of females $(n=13)$ was also small in their study. In turn, in the "total population group" males were rated significantly higher than females by both parents and teachers, which lends support to the assumption that females are more competent in their social skills than males $[6,26]$. There is a clear overlap of symptoms at the behavioural level between children with AS and other high-functioning children with ASD based on the ICD-10 and DSM-IV criteria for ASDs. No significant ASSQ score difference was found between the children with AS and HFA (Fig. 2), showing that differential diagnosis between AS and HFA cannot be made by using the ASSQ.

In Finland, primary school teachers get to know their pupils and their behaviour well, because there is one main teacher for each class group who teaches the same pupils for many hours every day from one to several years. Thus, it can be assumed that both parents and teachers know the behaviour of the children quite well, which might have yielded high concordance in the ratings. However, agreement between informants was slight $(\kappa=0.207)$, and even negative correlation $(r=-0.368)$ was found between parents' and teachers' ratings in the higher scoring "validation sample". This might indicate that the differences in behaviour between home and school are real. In addition, the 
Table 2 Statistics in parents', teacher's and summed parents' and teacher's scores in the "validation sample"

\begin{tabular}{|c|c|c|c|c|c|c|c|c|}
\hline Score & $\mathrm{SE}$ & SP & $\mathrm{SE}+\mathrm{SP}$ & PPV & NPV & LR & $\%$ agreement & Карра (CI 95\%) \\
\hline Parent 8 & 1.00 & 0.35 & 1.35 & 0.18 & 1.00 & 1.54 & 43.3 & $0.12(0-0.43)$ \\
\hline Parent 10 & 0.85 & 0.47 & 1.32 & 0.19 & 0.96 & 1.61 & 51.9 & $0.13(0-0.42)$ \\
\hline Parent 11 & 0.77 & 0.52 & 1.29 & 0.19 & 0.94 & 1.59 & 54.8 & $0.12(0-0.41)$ \\
\hline Parent 13 & 0.62 & 0.60 & 1.22 & 0.18 & 0.92 & 1.56 & 60.6 & $0.11(0-0.38)$ \\
\hline Parent 17 & 0.54 & 0.70 & 1.24 & 0.21 & 0.91 & 1.81 & 68.3 & $0.14(0-0.40)$ \\
\hline Teacher 16 & 1.00 & 0.44 & 1.44 & 0.21 & 1.00 & 1.80 & 51.4 & $0.17(0-0.45)$ \\
\hline Teacher 19 & 0.92 & 0.53 & 1.45 & 0.22 & 0.98 & 1.98 & 58.3 & $0.19(0-0.46)$ \\
\hline Teacher 20 & 0.85 & 0.60 & 1.45 & 0.23 & 0.96 & 2.12 & 63.1 & $0.21(0-0.47)$ \\
\hline Teacher 22 & 0.85 & 0.69 & 1.54 & 0.28 & 0.97 & 2.72 & 70.9 & $0.29(0.05-0.52)$ \\
\hline Teacher 23 & 0.69 & 0.76 & 1.45 & 0.29 & 0.94 & 2.83 & 74.8 & $0.28(0.04-0.52)$ \\
\hline Teacher 27 & 0.69 & 0.91 & 1.60 & 0.53 & 0.95 & 7.79 & 88.3 & $0.53(0.30-0.77)$ \\
\hline Parent + teacher 30 & 1.00 & 0.73 & 1.73 & 0.35 & 1.00 & 3.75 & 76.7 & $0.41(0.20-0.62)$ \\
\hline Parent + teacher 31 & 0.85 & 0.73 & 1.58 & 0.31 & 0.97 & 3.17 & 74.8 & $0.34(0.11-0.57)$ \\
\hline Parent + teacher 33 & 0.85 & 0.78 & 1.63 & 0.36 & 0.97 & 3.81 & 78.6 & $0.39(0.17-0.61)$ \\
\hline Parent + teacher 35 & 0.85 & 0.80 & 1.65 & 0.38 & 0.97 & 4.23 & 80.6 & $0.42(0.20-0.64)$ \\
\hline Parent + teacher 36 & 0.77 & 0.82 & 1.59 & 0.39 & 0.96 & 4.33 & 81.6 & $0.41(0.19-0.64)$ \\
\hline Parent + teacher 38 & 0.69 & 0.88 & 1.57 & 0.45 & 0.95 & 5.66 & 85.4 & $0.46(0.23-0.70)$ \\
\hline
\end{tabular}

$S E$ sensitivity, $S P$ specificity, $P P V$ positive predictive value, $N P V$ negative predictive value, $L R$ likelihood ratio, $C I$ confidence interval

teacher observes the child's behaviour in a group, having a better chance to notice behaviour abnormalities in social interaction than the parents who may have no opportunity to compare their child with peers. As described, the teachers were given an information package concerning the study, including lectures on AS and the ASSQ. By receiving information, the teachers may have been better aware than parents as to what kind of features they were supposed to assess. This might skew the correlation between informants in the "total population group". In Oulu, the biggest municipality of this study and the capital of Northern Ostrobothnia, we were able to obtain the information that teachers from 14 schools did not took in the lectures on AS and the ASSQ. However, in spite of the fact that these teachers were not trained, agreement between informants was slight (0.097), and in high-scoring ASSQs (parent $\geq 7$, or teacher $\geq 9)$, correlation was negative $(r=-0.421)$ between parents' and teachers' ratings, being in concordance with the results of the high-scoring "validation sample". In contrast, Swedish and Norwegian researchers have reported a stronger association between parents' and teachers' ratings on the ASSQ. Ehlers et al. [10] reported marked interrater reliability (Pearson $r=0.66$ ) of the ASSQ mean total score for parents' and teachers' ratings in children $(n=105)$ who were consecutively referred to the child neuropsychiatric clinic, and the correlation across informants for children with ASD $(n=20)$ was also marked $(r=0.77)$ in their study. In turn, Posserud et al. [19] reported a moderate correlation of 0.48 between teacher and parent score for boys and a low correlation of 0.34 between informants for girls on the ASSQ in a population sample of 9,430 children. For the whole, scale agreement between parents and teachers was 0.40 (weighted kappa) in the study of Posserud et al. [19].

The first stage of the ASSQ validation was to find out whether the original cut-offs are workable in the "outpatient group". Our results showed that only two subjects with ASD fell below the original parent and teacher cutoffs (parent ASSQ $<19$, teacher ASSQ $<22$ ). In addition, none of the outpatient children with ASD were rated below both minimum scores with $95 \%$ sensitivity based on the ROC curves in the study of Ehlers et al. [10] (parent ASSQ $<7$, teacher ASSQ < 9).

After the first stage of the ASSQ validation, we proceeded to the second phase to evaluate the statistics of the ASSQ. For this reason, all potential children with ASD $[10,12]$ were selected from the "total population study" to make up a "validation sample" in which the ASSQ validation was evaluated. Generalizations of the validity findings might be limited to the clinical settings when diagnosing higher-functioning patients who are suspected to have AS or autism. Generalization to whole population screening has to be treated with caution because the "validation sample" was not selected randomly. We gave up random selection because of the low number of ASD diagnoses in total population [e.g. 3, 23].

Based on our results, the use of the original Swedish cutoff of 22 [10] with $85 \%$ sensitivity and $69 \%$ specificity for teacher ASSQ score is indicated in Finland as well. In contrast, Ehlers et al. [10] reported poorer sensitivity 
$(65-70 \%)$ and better specificity $(91 \%)$ for the teacher cut-off score of 22. However, according to our results the ASSQ seems to work best by using a summed parents' and teacher's score. In clinical settings, it is important to screen all potential ASD subjects. Thus, the cut-off score of 30 for the summed parents' and teacher's score is recommended to be used in clinical settings with $100 \%$ sensitivity and $73 \%$ specificity. Ehlers et al. [10] estimated the cut-off score of 19 for parents' ratings with the sensitivity of $62-82 \%$ and the specificity of $90 \%$. Importantly, in Finland the ASSQ seemed to be invalid in identifying subjects with AS/autism, if single rating by parents was used: if sensitivity was high, specificity was low, and vice versa. Thus, there is a strong caution against the use of single ASSQ rating by parents when screening higher-functioning children with suspected AS/autism.

This study showed that the Finnish ASSQ works as a screening instrument with some limitations. The ASSQ identifies the majority of higher-functioning children with AS/autism by using the summed parents' and teacher's score or by using single rating by teacher. NPVs $(1.00 ; 0.97)$ were excellent, showing that no children with AS/autism fell below the cut-offs in summed parents' and teacher's ratings and only few children in single ratings by teacher; i.e. it is unlikely that a child has AS/autism if rated below the cut-off scores in summed parents' and teacher's or in single teacher's rating. However, PPVs $(0.35 ; 0.28)$ were very low, indicating that many subjects without a registered AS or autism diagnosis were rated above the cut-offs in summed parents' and teacher's ratings and in single teacher's ratings. In turn, Ehlers et al. [10] did not report any PPV or NPV values in their study. Our validation findings are preliminary; research is ongoing and more results are expected later.

\section{Conclusions}

First, because of the low PPV it is emphasized that the ASSQ is a screening instrument, not a diagnostic instrument; all screening-positive children have to undergo diagnostic examinations.

Second, this article points out the importance of using multiple informants, as also suggested by previous studies concerning ASDs [e.g. 3, 18-20, 24]. Although the cut-off score could not be estimated for single parent ratings, the cut-off score for summed parents' and teacher's ratings turned out to be the best.

Acknowledgments We want to thank the children and their parents, the teachers and the entire staff of the schools for participating in this study. We thank chief psychologist Terttu Tapio and clinical psychologist Kati Wedman for their comments and help with this study. The Graduate School of Circumpolar Wellbeing, Health and Adaptation is acknowledged for their support. This study received financial support from Finland's Slot Machine Association awarded to the Finnish Association for Autism and Asperger's Syndrome and from the Child Psychiatric Research Foundation, Finland, awarded to the Eija and Veikko Lesonen Foundation, Oulu, Finland. Dr. Marja-Leena Mattila received research grants from the Rinnekoti Research Foundation, Espoo, Finland, the Alma and K. A. Snellman Foundation, Oulu, Finland, the Child Psychiatric Research Foundation, Finland, the Child Psychiatric Research Foundation, Oulu Area, Finland, and the Oulu Medical Research Foundation, Oulu, Finland. Psychologist Katja Jussila received a research grant from the Alma and K. A. Snellman Foundation, Oulu, Finland, and psychologist Sanna Kuusikko from the Alma and K. A. Snellman Foundation Oulu, Finland, and the Child Psychiatric Research Foundation, Finland. This particular study was also financially supported by a National Alliance for Autism Research (NAAR) grant awarded to professor David Pauls.

\section{References}

1. Achenbach TM, McConaughy SH, Howell CT (1987) Child/ adolescent behavioral and emotional problems: implications of cross-informant correlations for situational specificity. Psychol Bull 101:213-232

2. American Psychiatric Association (1994) Diagnostic and statistical manual of mental disorders, 4th edn. American Psychiatric Association, Washington, DC

3. Baird G, Simonoff E, Pickles A, Chandler S, Loucas T, Meldrum D, Charman T (2006) Prevalence of disorders of the autism spectrum in a population cohort of children in South Thames: the Special Needs and Autism Project (SNAP). Lancet 15:210-215

4. Baron-Cohen S, Allen J, Gillberg C (1992) Can autism be detected at 18 months? The needle, the haystack, and the CHAT. Br J Psychiatry 161:839-843

5. Baron-Cohen S, Cox A, Baird G, Swettenham J, Nightingale N, Morgan K, Drew A, Charman T (1996) Psychological markers in the detection of autism in infancy in a large population. Br J Psychiatry 168:158-163

6. Baron-Cohen S, Wheelwright S, Skinner R, Martin J, Clubley E (2001) The autism-spectrum quotient (AQ): evidence from Asperger syndrome/high-functioning autism, males and females, scientists and mathematicians. J Autism Dev Disord 31:5-17

7. Berument SK, Rutter M, Lord C, Pickles A, Bailey A (1999) Autism screening questionnaire: diagnostic validity. Br J Psychiatry 175:444-451

8. Constantino JN, Davis SA, Todd RD, Schindler MK, Gross MM, Brophy SL, Metzger LM, Shoushtari CS, Splinter R, Reich W (2003) Validation of a brief quantitative measure of autistic traits: comparison of the social responsiveness scale with the autism diagnostic interview-revised. J Autism Dev Disord 33:427-433

9. Ehlers S, Gillberg C (1993) The epidemiology of Asperger syndrome. A total population study. J Child Psychol Psychiatr 34:1327-1350

10. Ehlers S, Gillberg C, Wing L (1999) A screening questionnaire for Asperger syndrome and other high-functioning autism spectrum disorders in school age children. J Autism Dev Disord 29:129-141

11. Howlin P, Asgharian A (1999) The diagnosis of autism and Asperger syndrome: findings from a survey of 770 families. Dev Med Child Neurol 41:834-839

12. Kadesjo B, Gillberg C, Hagberg B (1999) Brief report: autism and Asperger syndrome in seven year-old children: a total population study. J Autism Dev Disord 29:327-331

13. Krug DA, Arick J, Almond P (1980) Behavior checklist for identifying severely handicapped individuals with high levels of autistic behavior. J Child Psychol Psychiatr 21:221-229 
14. Kumpulainen K, Rasanen E, Henttonen I, Moilanen I, Piha J, Puura K, Tamminen T, Almqvist F (1999) Children's behavioural/emotional problems: a comparison of parents' and teachers' reports for elementary school-aged children. Eur Child Adolesc Psychiatry 8:41-47

15. Lesinskiene S (2000) Vilniaus miesto vaiku autizmas, Vilniaus Universitetas, Daktaro disetacijos santrauka, Biomedicinos mokslai, medicina 07B, psichiatrija B650. Vilnius, Lithuania

16. Lord C, Rutter M, Le Couteur A (1994) Autism Diagnostic Interview-Revised: a revised version of a diagnostic interview for caregivers of individuals with possible pervasive developmental disorders. J Autism Dev Disord 24:659-685

17. Lord C, Risi S, Lambrecht L, Cook EH Jr, Leventhal BL, DiLavore PC, Pickles A, Rutter M (2000) The autism diagnostic observation schedule-generic: a standard measure of social and communication deficits associated with the spectrum of autism. J Autism Dev Disord 30:205-223

18. Mattila ML, Kielinen M, Jussila K, Linna SL, Bloigu R, Ebeling H, Moilanen I (2007) An epidemiological and diagnostic study of Asperger syndrome according to four sets of diagnostic criteria. J Am Acad Child Adolesc Psychiatry 46:636-646

19. Posserud MB, Lundervold AJ, Gillberg C (2006) Autistic features in a total population of 7-9-year-old children assessed by the ASSQ (Autism Spectrum Screening Questionnaire). J Child Psychol Psychiatry 47:167-175

20. Risi S, Lord C, Gotham K, Corsello C, Chrysler C, Szatmari P, Cook EH Jr, Leventhal BL, Pickles A (2006) Combining information from multiple sources in the diagnosis of autism spectrum disorders. J Am Acad Child Adolesc Psychiatry 45:1094-1103

21. Rutter M, Bailey A, Lord C (2003) SCQ: social communication questionnaire. Western Psychological Services, Los Angeles, CA

22. Scott FJ, Baron-Cohen S, Bolton P, Brayne C (2002) The CAST (Childhood Asperger Syndrome Test): preliminary development of a UK screen for mainstream primary-school-age children. Autism 6:9-31

23. Sponheim E, Skjeldal O (1998) Autism and related disorders: epidemiological findings in a Norwegian study using ICD-10 diagnostic criteria. J Autism Dev Disord 28:217-227

24. Szatmari P, Archer L, Fisman S, Streiner DL (1994) Parent and teacher agreement in the assessment of pervasive developmental disorders. J Autism Dev Disord 24:703-717

25. Wechsler D (1991) Wechsler Intelligence Scale for Children, 3rd edition (WISC-III). Psychological Corporation, New York

26. Williams JG, Allison C, Scott FJ, Bolton PF, Baron-Cohen S, Matthews FE, Brayne C (2008) The Childhood Autism Spectrum Test (CAST): sex differences. J Autism Dev Disord 38:17311739

27. Williams J, Scott F, Stott C, Allison C, Bolton P, Baron-Cohen S, Brayne C (2005) The CAST (Childhood Asperger Syndrome Test): test accuracy. Autism 9:45-68

28. World Health Organisation (1993) International Classification of Mental and Behavioural Disorders (ICD-10). Diagnostic criteria for research. WHO, Geneva 